\title{
A knowledge based hierarchical reliability allocation (HIRAL) approach for shipboard systems
}

Kadir Cicek ( $\nabla$ cicekk@itu.edu.tr )

Original Article

Keywords: Ship-board Systems, Reliability Allocation Analysis, Analytic Hierarchy Process (AHP), Data Envelopment Analysis (DEA), Feasibility of Objectives (FOO)

Posted Date: May 29th, 2020

DOI: https://doi.org/10.21203/rs.3.rs-31634/v1

License: (c) (1) This work is licensed under a Creative Commons Attribution 4.0 International License. Read Full License 


\title{
A knowledge based hierarchical reliability allocation (HIRAL) approach for shipboard systems
}

\author{
Kadir CICEK ${ }^{\mathrm{a}, *}$ \\ ${ }^{a}$ Marine Engineering Department, Maritime Faculty, Istanbul Technical University, \\ 34940, Tuzla, Istanbul, Turkey,
}

\begin{abstract}
Reliability has become a greater concern in ship-board systems due to increasing technology, system complexity and multiple design demands. Enhancement the reliability of ship-board systems promotes to ensure safe and continuous operation onboard a ship. To enhance the reliability of ship-board system, it is essential to figure out each individual component reliability. Within this scope, reliability allocation analysis turns into an onerous task to enhance the reliability of ship-board systems through identification of possible component-based design, construction and operation optimizations. This study proposes a hybrid reliability allocation methodology based on hierarchical structure with the integration of analytic hierarchy process (AHP), data envelopment analysis (DEA) and feasibility of objectives (FOO) methods. The proposed methodology provides reliability allocation analysis for systems with any number of components. Also, the study figures out the usefulness of the adaptation of AHP-DEA into reliability allocation analysis. To demonstrate the applicability of proposed methodology, a case study on steering gear system is presented.
\end{abstract}

Keywords: Ship-board Systems, Reliability Allocation Analysis, Analytic Hierarchy Process (AHP), Data Envelopment Analysis (DEA), Feasibility of Objectives (FOO)

* Corresponding author: tel: +90 216395 1064, fax: +90 216395 4500, email address: cicekk@itu.edu.tr 


\section{Introduction}

With development of complex and technologically advanced large scale systems, such as nuclear power plants, space systems, petrochemical/chemical plants, offshore units, and ship-board systems, issues dealing with reliability of complex systems have become an even greater concern in recent years. Specially, the increasing technology, system complexity and multiple design demands of ship-board systems and cost reduction on a highly competitive market bring the reliability forward as a substantial point for clients and utilizers. High reliability ship-board systems pay close attention to complement many nonsafe elements and to contribute safe operation on board ship. However, manufacturers still have difficulties in improving the reliability of ship-board systems by reason of their specific characteristics and harsh operating environment that make them stand apart from the conventional land systems.

The reliability of system is affected by many factors such as system operating environment, condition indicating parameters, and human aspects which can degrade or improve the reliability other than the system operating time (Ghodrati, 2005). Reliability practitioners are spending considerable research effort and expense to develop appropriate principles for ascertaining the engineering systems reliability. Nowadays, the primary focus on reliability of the system is to translate the reliability requirement of the systems into each individual component for the determination of overall system reliability. The fulfillment of component based requirements increases the overall system reliability to meet the overall requirements (Guo et al., 2014). At this insight, a proper reliability allocation method needs to be implemented to allocate required system reliability to its constituent components proportionately. It is necessary to take into consideration a wide range of factors in the allocation of reliability requirements including component criticality, complexity, operating environment, operating time, state-of-the-art, cost and several other factors (Yadav \& Zhuang, 2014).

Having relevant and sufficient large set of qualitative or quantitative data on these factors related to the analyzed system is an important issue for appropriate reliability allocation. From the perspective of ship-board systems, however reliability allocation analysis is quite onerous task due to uncertainty and inadequacy of quantitative system data. To overcome these limitations, the study concentrates primarily on adoption of expert judgements as a source of information in reliability allocation for ship-board systems. Additionally, in the study, reliability allocation analysis is considered as a multi criteria decision making 
(MCDM) problem with its multiple factor structure. In this viewpoint, a hybrid reliability allocation methodology integrating two different MCDM methods, analytic hierarchy process (AHP) and data envelopment analysis (DEA) is introduced. Under limited system based data circumstance, proposed methodology allows us to utilize experts' judgements as a source of information and also it provides opportunity to handle multiple experts' judgements. A growing number of experts doing analysis in reliability allocation increases consistency and certainty of the elicited judgments.

The proposed methodology introduces a new understanding in reliability allocation analysis through providing analysis under uncertain and inadequate data for ship-board systems. The integration of AHP and DEA methods helps to retain individual advantages and to overcome individual shortcomings of these methods, insofar as the proposed methodology has an ability to handle a system with any number of components. Besides, this research work extends the literature by weighting the reliability allocation factors in relationship to each other. Furthermore, with its generic system analysis structure, the proposed methodology provides comprehensive reliability allocation analysis solution not only for ship-board systems but also other complex and large-scale systems.

The paper is organized as follows: Section 1 gives a brief introduction about the importance of reliability allocation analysis for ship-board systems. In Section 2 I give an overview of related literature. I present formulation of the proposed HIRAL methodology in Section 3. The applicability of the methodology is demonstrated with a case study on one of the critical ship-board systems onboard ship; steering gear systems in Section 4. The paper is concluded and discussed some future research directions in Section 5.

\section{Literature review: methodological perspective}

Since the middle of the 20th century, there has been tremendous research efforts and progress on reliability allocation analysis. Within these studies considering methodological development on reliability allocation analysis it is observed that, the characteristics of the systems were substantially influence the structures of the methodologies. By virtue of the fact that, in the literature it is possible to find many different methodologies on reliability allocation analysis. One of the earliest methodology in literature is Advisory Group on Reliability of Electronic Equipment (AGREE) method (Advisory Group of Reliability of Electronic Equipment, 1957). AGREE method takes into account unit or subsystem complexity and criticality. In 1964 Aeronautical Radio Incorporated proposed the ARINC apportionment technique which is based on the failure rates of units or subsystems (Alven, 
1964). Within the same year, Bracha (1964) presented an allocated reliability method using four factors: state-of-the-art, subsystem complexity, environmental conditions, and relative operating time. In following year (1965), Karmiol introduced reliability allocation method using the factors: complexity, state-of-the-art, operational profile, and criticality of the system. The engineering design guide, Reliability Design Handbook (Anderson, 1976), proposed the feasibility-of-objectives (FOO) method. System intricacy, state of the art, performance time, and environmental conditions considered as allocation factors in FOO method. In 1992, Boyd developed Boyd method with incorporating the Equal and ARINC methods. Balaban and Jeffers (1999) proposed Base method. Base method considers the units of the investigated system in series. Kuo (1999) in his book "Reliability Assurance: Application for engineering and management", introduced an average weighting allocation method as a guide for commercial reliability allocation analysis. These methodologies are accepted as traditional methodologies and they have wide applicability in reliability allocation analysis across many industries. However, the traditional methodologies have two important shortcomings: the first one is not considering the ordered weight of the reliability allocation factors and the second one is not able to manage fuzzy or ambiguous information in reliability allocation.

To minimize the shortcomings of traditional methods, intensive research efforts have been carried out on methodological aspects in the literature. MCDM methods are frequently preferred in allocation processes to consider the ordered weight of reliability allocation factors. In the literature review it is found that, AHP is mostly utilized MCDM method. The studies of the authors Zahedi and Ashrafi (1991), Zhang and Liao (2009), Cheng et al. (2014), Chatterjee et al. (2015), Subhashis et al. (2015), Chen et al. (2016), Di Bona et al. (2016), Li et al. (2016), Ma et al. (2016) and Di Bona and Forcina (2017) can be given as example studies of using AHP in reliability allocation process. Decision making trial and evaluation laboratory (DEMATEL) method besides the AHP is another preferred MCDM method in the literature. Liaw et al. (2011) and Chang et al. (2013) adopt the DEMATEL method to consider indirect relations between subsystems or components in reliability allocation. Liaw et al. (2011) and Chang et al. (2013) adopt the DEMATEL method to consider indirect relations between subsystems or components in reliability allocation. Also, Li et al. (2017) proposed a reliability allocation model based on another popular MCDM method: Grey System Theory considering 6 effecting factors such as the 
importance, complexity, technology development level, manufacturing level, working time and environmental conditions.

Apart from the MCDM methods aforementioned, multi objective optimization methods (Malec, 1977; Sakawa, 1978; Cho et al., 1987; Bari et al., 1985; Rao and Dhingra, 1992; Liu \& Li, 2003; Zavala, 2005; Zhao et al., 2005; Zio and Bazzo, 2011; Zhang and Wu, 2012; Zio and Bazzo, 2012; Sangeetha et al., 2014; Li et al., 2014; Falcone et al., 2018), integrated factors method (Falcone, Silvestri and Di Bona, 2003), genetic algorithm method (Yang et al., 1999; Lu et al., 2004; Kumral, 2005; Zia and Coit, 2006; Xu et al., 2007; Liu et al., 2007; Liao 2009; Li et al., 2015), Markov Chain (Ke-Rong et al., 2001), Bayesian network (Qian et al., 2012; Ma et al., 2016;), FMEA (Chang et al., 2013; Sadeghi et al., 2014; Wang et al., 2016), Monte Carlo (Fan et al., 2014; Li \& Li, 2014; Li et al., 2015; ), critical flow method (Silvestri et al., 2015) and data envelopment analysis method (Zhang \& Huang, 2016) are other important methods used in the literature to minimize the shortcomings of traditional reliability allocation methods.

It is figured out from the literature review that most of the contemporary methodologies need vast amount of system data for appropriate reliability allocation analysis. However, from the ship-board systems perspective it is not possible to find sufficient, relevant and consistent data on system reliability. This situation makes experts' judgements essential source of data on system reliability. On the other hand, the proposed methodologies could not guarantee efficient access and constant exchange of large amounts of expert measurement information on reliability allocation analysis (Feng et al., 2017). Additionally, existing reliability allocation methods can meet the requirements of reliability allocation for simple or specific systems (Liang, 2015).

For these reasons, methodological improvements in reliability allocation analysis still can be considered as a crucial issue to research on. Allocation analysis under limited information, evaluation of expert judgements as system reliability information, aggregation of multiple expert judgements and ship-board system can be listed as potential methodological improvement points. To provide solutions on the aforementioned gaps in the literature, this paper prompts a hybrid reliability allocation analysis method to implement reliability allocation in ship-board systems. 


\section{Proposed methodology}

In this section, we initially describe theoretical background of methods used in proposed approach. In the methodology, AHP is used to determine the importance degree of each reliability allocation factor (RAF). Calculation of the importance degrees of RAFs provides inclusion of system features and characteristics into allocation process. In parallel with the calculation of the importance degrees of RAFs, DEA is used to empirically measure reliability rating of each component for each RAF with the help of multiple of experts' judgements. The motivation behind using multiple experts in allocation analysis is to obtain more comprehensive information that can lead to more accurate forecasts or estimates and, ultimately, to better reliability allocation. The outputs generated by AHP; weights of RAFs; and DEA; individual reliability ratings; are used as inputs for FOO in its mathematical structure. The general framework of the proposed method is graphically illustrated in Figure 1. 




Figure 1. Framework of the methodology

The detailed information on AHP, DEA and FOO methods are presented in subsections respectively.

\subsection{Analytic Hierarchy Process (AHP)}

Analytic Hierarchy Process (AHP), introduced by Thomas Saaty (1980), is the most commonly preferred multi decision making (MCDM) method in the literature. AHP mainly incorporates decomposing the decision problem into a hierarchical structure, collection of data and measurement through pairwise comparisons and calculation of the weights, importance degree, of attributes in each level. The Saaty's relative importance scale illustrated in Table 1 is used for the quantification of pairwise comparisons (Saaty, 1980; 1994). The pairwise comparisons are then adopted in a square pairwise comparison matrix to obtain the relative importance degree of attributes at a particular level of the AHP. 
Table 1. Saaty's scale of relative importance (Saaty, 1986)

\begin{tabular}{cc}
\hline Strength of importance & Description \\
\hline 1 & Equally preferred \\
2 & Between equal and moderate \\
3 & Moderately preferred \\
4 & Between moderate and strong \\
5 & Strongly preferred \\
6 & Between strong and very strong \\
7 & Very strongly preferred \\
8 & Between very strong and extreme \\
9 & Extremely preferred \\
Reciprocals & Reciprocals for inverse comparison \\
\hline
\end{tabular}

The process of applying AHP is starting with construction of the pairwise comparison matrix by asking the expert questions to indicate the relative importance of allocation factors. From the pairwise comparison matrix A, the priority weights of factors are determined by solving the following equation:

$$
A w=\lambda_{\max } w, w=\left(w_{1}, w_{2}, \cdots, w_{n}\right)^{T}
$$

$\lambda_{\max }$ represents the maximum eigenvalue of $\mathrm{A}$. After carrying out pairwise comparisons, to verify the pairwise comparison matrix consistency is acceptable or not, the consistency ratio $(\mathrm{CR})$ of the matrix is calculated using the following equation:

$$
C R=\frac{\left(\lambda_{\max }-n\right)(n-1)}{R I}
$$

RI states a random consistency index, whose value varies with the order of pairwise comparison matrix. In Table 2, RI values for the pairwise comparison matrices with the order from 1 to 10 are presented. If the consistency ratio is smaller or equal to 0.10 , the comparison matrix A is accepted consistent, otherwise the comparison matrix is accepted as inconsistent and it is required to be reviewed and improved.

Table 2. Random consistency index R.I. (Saaty 1986)

\begin{tabular}{cccccccccc}
\hline $\mathrm{n}$ & 2 & 3 & 4 & 5 & 6 & 7 & 8 & 9 & 10 \\
\hline $\mathrm{RI}$ & 0 & 0.58 & 0.90 & 1.12 & 1.24 & 1.32 & 1.41 & 1.45 & 1.49 \\
\hline
\end{tabular}




\subsection{Data Envelopment Analysis (DEA)}

Data envelopment analysis (DEA), a well-known method for measuring efficiency between decision making units (DMUs), was introduced by Charnes et al. (1978) which transforms the fractional linear measure of efficiency into a linear programming model (Aldamak \& Zolfaghari, 2017). It can be used a decision analysis tool because it classifies all system units under assessment into two groups: efficient and inefficient. In practical applications, decision makers (DMs) are typically not just interested in classifying data into efficient and inefficient; by a majority, they wish to rank all units under evaluation (Aldamak \& Zolfaghari, 2017). In literature to overcome this discriminatory problem of DEA, modified approaches were introduced to rank all DMUs under assessment. Specially, DEA approaches that have applied multiple criteria decision making (MCDM) concept in order to rank DMUs in DEA standard models are mostly preferred in literature. At this insight, this paper uses advantages of DEA ranking model introduced by Wang et al. (2008) to rank system units dealing with ordinal data. Wang et al.'s (2008) approach is constituted to analyse complex multi component systems and structures. It provides a reasonable compromise between accuracy and simplicity in aggregation of multiple experts' judgements. The general definitions and steps of the Wang's et al. (2008) methodology can be explained as follows;

To describe the relative importance of each system component with respect to RAFs, a set of assessment grades are defined for each RAF; $G=\left\{H_{j 1_{j}}, H_{j 2_{j}}, \cdots, H_{j K_{j}}\right\}(j=$ $1,2, \ldots, m) . H_{j 1_{j}}, H_{j 2_{j}}, \cdots, H_{j K_{j}}$ represent the importance from the most to least important where $K_{j}$ is the number of assessment grades for RAF $j$. This definition helps us to assess different RAFs using different numbers of assessment grades. In the study, the linguistic assessment grades presented in Table 3 are used. The linguistic assessment grades provide more meaningful and manageable assessment. Additionally, it helps to handle complexity and uncertainty of objective thing and the fuzziness of human thought. 
Table 3. Linguistic assessment grades of RAFs

\begin{tabular}{|c|c|c|c|c|c|c|c|}
\hline \multicolumn{8}{|c|}{ Intricacy $\left(\boldsymbol{R} \boldsymbol{A} \boldsymbol{F}_{\boldsymbol{l}}\right)$} \\
\hline Very simple & (VS) & Simple & $(\mathbf{S})$ & Complex & (C) & Very complex & $(\mathrm{VC})$ \\
\hline \multicolumn{8}{|c|}{ State of the art $\left(\boldsymbol{R} \boldsymbol{A} \boldsymbol{F}_{2}\right)$} \\
\hline Very Low & $(\mathrm{VL})$ & Low & $(\mathrm{L})$ & High & $(\mathrm{H})$ & Very high & $(\mathrm{VH})$ \\
\hline \multicolumn{8}{|c|}{ Operating time $\left(\boldsymbol{R} \boldsymbol{A} \boldsymbol{F}_{3}\right)$} \\
\hline Very Low & $(\mathrm{VL})$ & Low & $(\mathrm{L})$ & High & $(\mathrm{H})$ & Very high & $(\mathrm{VH})$ \\
\hline \multicolumn{8}{|c|}{ Environmental conditions $\left(\boldsymbol{R A} \boldsymbol{F}_{4}\right)$} \\
\hline Least Severe & (LS) & Moderately severe & (MS) & Severe & (S) & Very severe & (VS) \\
\hline
\end{tabular}

The reliability allocation is structured on four factors which are described in FOO method: intricacy, state-of-the-art, operating time and environmental conditions. The Intricacy factor, $R A F_{1}$, represent how intricate the element. The least intricate element is rated as very simple (VS), and the most highly intricate element is rated as very complex (VC). The state-of-the-art factor, $R A F_{2}$, represents how technologically up-to-date the element is. The least developed element is assigned a value of very low (VL), and the most highly developed is assigned a value of very high $(\mathrm{VH})$. The operating time factor, $R A F_{3}$, represents how continuously the element is in operation. The element that operates for the entire mission time is rated very high $(\mathrm{VH})$, and the element that operates the for the least mission time is rated as very low (VL). The Environment factor, $R A F_{4}$, represents how harsh the element's environment is. The elements expected to experience harsh environments during their operation are rated as very severe (VS), and those expected to encounter the least severe environments are rated as least severe (LS).

The experts assess the system components respect to the four RAFs in terms of their relative importance. The assessment results of system components assessed by experts are defined by following distribution assessment vectors:

$R\left(C_{j}\left(A_{i}\right)\right)=\left\{\left(H_{j 1}, N E_{i j 1}\right), \ldots,\left(H_{j K_{j}}, N E_{i j K_{j}}\right)\right\}, i=1, \ldots, n ; j=1, \ldots, m$

where $N E_{i j k}\left(\mathrm{k}=1, \ldots, \mathrm{K}_{\mathrm{j}}\right)$ represent the numbers of experts who assess system component $\mathrm{C}_{\mathrm{i}}$ to grade $\mathrm{H}_{\mathrm{jk}}$ under the RAF $j$. Then, the obtained distribution assessment vectors are transformed into the belief structure as below (Yang, 2001);

$B\left(C_{j}\left(A_{i}\right)\right)=\left\{\left(H_{j 1}, b_{i j 1}\right), \ldots,\left(H_{j K_{j}}, b_{i j K_{j}}\right)\right\}, i=1, \ldots, n ; j=1, \ldots, m$,

where $b_{i j k}=N E_{i j k} / N_{j}$ with $0 \leq b_{i j k} \leq 1$ for $i=1, \ldots, n, k=1, \ldots, K_{j}$, and $j=1, \ldots, m$. 
All the distribution assessment vectors form a distribution assessment matrix illustrated in Table 4, where $\sum_{k=1}^{K_{j}} N E_{i j k}=N_{j}$ for $i=1, \ldots, n$ and $j=1, \ldots, m$.

Table 4. Distribution assessment matrix for system components

\begin{tabular}{|c|c|c|c|c|c|c|c|c|c|c|c|}
\hline \multirow{3}{*}{ Components } & \multicolumn{11}{|c|}{ Reliability Allocation Factors } \\
\hline & \multicolumn{3}{|l|}{$R A F_{1}$} & \multirow{2}{*}{$\begin{array}{l}\cdots \\
\ldots \\
\ldots\end{array}$} & \multicolumn{3}{|l|}{$R A F_{j}$} & \multirow{2}{*}{$\begin{array}{l}\cdots \\
\cdots \\
\ldots\end{array}$} & \multicolumn{3}{|l|}{$R A F_{m}$} \\
\hline & $H_{11}$ & $\cdots$ & $H_{1 K_{1}}$ & & $H_{j l}$ & $\cdots$ & $H_{j K_{j}}$ & & $H_{m l}$ & $\cdots$ & $H_{m K_{m}}$ \\
\hline$C_{l}$ & $N E_{111}$ & $\cdots$ & $N E_{11 K_{1}}$ & $\cdots$ & $N E_{1 j 1}$ & $\cdots$ & $N E_{1 j K_{j}}$ & $\cdots$ & $N E_{1 m 1}$ & $\cdots$ & $N E_{1 m K_{m}}$ \\
\hline$\vdots$ & $\vdots$ & $\cdots$ & $\vdots$ & $\cdots$ & $\vdots$ & $\cdots$ & $\vdots$ & $\cdots$ & $\vdots$ & $\cdots$ & $\vdots$ \\
\hline$C_{i}$ & $N E_{i l 1}$ & $\cdots$ & $N E_{i 1 K_{1}}$ & $\cdots$ & $N E_{i j 1}$ & $\cdots$ & $N E_{i j K_{j}}$ & $\cdots$ & $N E_{i m 1}$ & $\cdots$ & $N E_{i m K_{m}}$ \\
\hline$\vdots$ & $\vdots$ & $\cdots$ & $\vdots$ & $\cdots$ & $\vdots$ & $\cdots$ & $\vdots$ & $\cdots$ & $\vdots$ & $\cdots$ & $\vdots$ \\
\hline$C_{n}$ & $N E_{n 11}$ & $\ldots$ & $N E_{n 1 K_{1}}$ & $\ldots$ & $N E_{n j 1}$ & $\ldots$ & $N E_{n j K_{j}}$ & $\ldots$ & $N E_{n m 1}$ & $\ldots$ & $N E_{n m K_{m}}$ \\
\hline
\end{tabular}

$s\left(H_{j k}\right)$ represents the scoring of grade $H_{j k}\left(k=1, \ldots, K_{j}\right)$. The individual reliability rating of each component with respect to every RAF can be defined as

$$
v_{i j}=\sum_{k=1}^{K_{j}} s\left(H_{j k}\right) N E_{i j k}, i=1, \ldots, n ; j=1, \ldots, m
$$

To determine individual reliability rating of each component with respect to every RAF, each system component defined as a decision making unit (DMU) and $s\left(H_{j k}\right)$ states the relative importance weight attached to the NEijk, the following DEA model developed by Wang et al. (2007) for preference voting and aggregation is constructed (Wang, Chin \& Yang, 2007; Wang et al., 2008):

\section{Maximize $\quad \alpha$}

$$
\begin{aligned}
& \text { Subject to } \quad \alpha \leq v_{i j}=\sum_{k=1}^{K_{j}} s\left(H_{j k}\right) N E_{i j k} \leq 1, i=1, \ldots, n, \\
& s\left(H_{j 1}\right) \geq 2 s\left(H_{j 2}\right) \geq \cdots \geq K_{j} s\left(H_{j K_{j}}\right) \geq 0,
\end{aligned}
$$

By solving the model (6) for each RAF, respectively, the individual reliability rating of each component with respect to $m R A F s$ is generated by equation (5). Then, the individual reliability ratings of components are aggregated into an overall reliability rating using the equation (7), as shown below: 


$$
W\left(C_{i}\right)=\sum_{j=1}^{m} w_{j} v_{i j}^{*}=\sum_{j=1}^{m} w_{j}\left(\sum_{k=1}^{K_{j}} s^{*}\left(H_{j k}\right) N E_{i j k}\right), \quad i=1, \ldots, n
$$

The obtained overall reliability ratings of the components use as inputs of FOO method.

\subsection{Feasibility of Objectives (FOO)}

Feasibility of objectives (FOO) method was first introduced in 1963 (Marah, 1963; Reliability, 1963). This method was developed primarily for allocating reliability in repairable electromechanical systems. Nowadays, it is widely used in commercial and military applications. Main philosophy of FOO in determination of component allocation scores is based on the relative difficulty of each component achieving high reliability (Kim $\&$ Zuo, 2015). Such difficulty for component $i$ is evaluated by four factors: intricacy $\left(R A F_{1}\right)$, state-of-the-art $\left(R A F_{2}\right)$, operating time $\left(R A F_{3}\right)$ and environmental conditions $\left(R A F_{4}\right)$. With its simple mathematical structure and a wide applicability in reliability allocation analysis, we integrate FOO in our proposed method.

The calculated overall reliability ratings, $\mathrm{W}\left(\mathrm{C}_{\mathrm{i}}\right)$, with the equation $(7)$ are used as inputs of the equation (8) for the calculation of the component complexity factor $\left(\mathbf{C}_{\mathbf{i}} \mathbf{i}\right)$ which is defined in FOO method.

$$
C_{i}^{\prime}=\frac{W_{j}}{\sum_{j=1}^{n} W_{j}}, \quad i=1, \ldots, n
$$

With the obtained component complexity factor, failure rate of $\mathrm{i}^{\text {th }}$ component, $\lambda_{k}$, is calculated with the help of defined equation as:

$$
\lambda_{k}=\lambda_{s} * C^{\prime}{ }_{i}, \quad i=1, \ldots, k
$$

After the calculation of failure rate of $i^{\text {th }}$ component, the allocated reliability of $i^{\text {th }}$ component $\left(\mathrm{R}_{\mathrm{i}}\right)$ is obtained with using the following equation:

$$
R_{i}=e^{-\lambda_{i} t}
$$

\section{Demonstration: Reliability allocation for steering gear system}

The proposed methodology is applied to a steering gear system which is one of the most critical elements in handling a ship. In addition to meet customers' requirements and marine industry standard, the reliability of steering gear system plays a significant role to 
assist the safe handling the ships. To produce highly reliable and durable ship-board systems will substantially contribute not only the safe handling the ships but also to take the next step in automation of the ships. From the design to operation stages of ship-board systems, reliability allocation is an important analytic tool to improve the system reliability. In the study, ram type steering gear system, as a commonly used steering gear type onboard ships, is selected for reliability allocation analysis. It consists of 3 major subsystems; telemotor, control unit and power unit. The complete subsystem and component list of ram type steering gear system is presented in table 5 .

Table 5. Subsystems and components of steering gear system

\begin{tabular}{|c|c|c|}
\hline Subsystem & Component & Code of component \\
\hline \multirow{3}{*}{ Telemotor } & Transmitter & $\mathrm{C}_{1}$ \\
\hline & Receiver & $\mathrm{C}_{2}$ \\
\hline & Charging unit & $\mathrm{C}_{3}$ \\
\hline \multirow[t]{6}{*}{ Control unit } & Control unit & $\mathrm{C}_{4}$ \\
\hline & Pump & $\mathrm{C}_{5}$ \\
\hline & Electric motor & $\mathrm{C}_{6}$ \\
\hline & Ram & $\mathrm{C}_{7}$ \\
\hline & Cylinder & $\mathrm{C}_{8}$ \\
\hline & Oil cooler & $\mathrm{C}_{9}$ \\
\hline \multirow[t]{6}{*}{ Power unit } & Cylinder isolating valve & $\mathrm{C}_{10}$ \\
\hline & By-pass valve & $\mathrm{C}_{11}$ \\
\hline & Safety valve & $\mathrm{C}_{12}$ \\
\hline & Sleeve & $\mathrm{C}_{13}$ \\
\hline & Crosshead & $\mathrm{C}_{14}$ \\
\hline & Tiller & $\mathrm{C}_{15}$ \\
\hline
\end{tabular}

The hierarchical structure of the reliability allocation for steering gear system is presented in Figure 2.

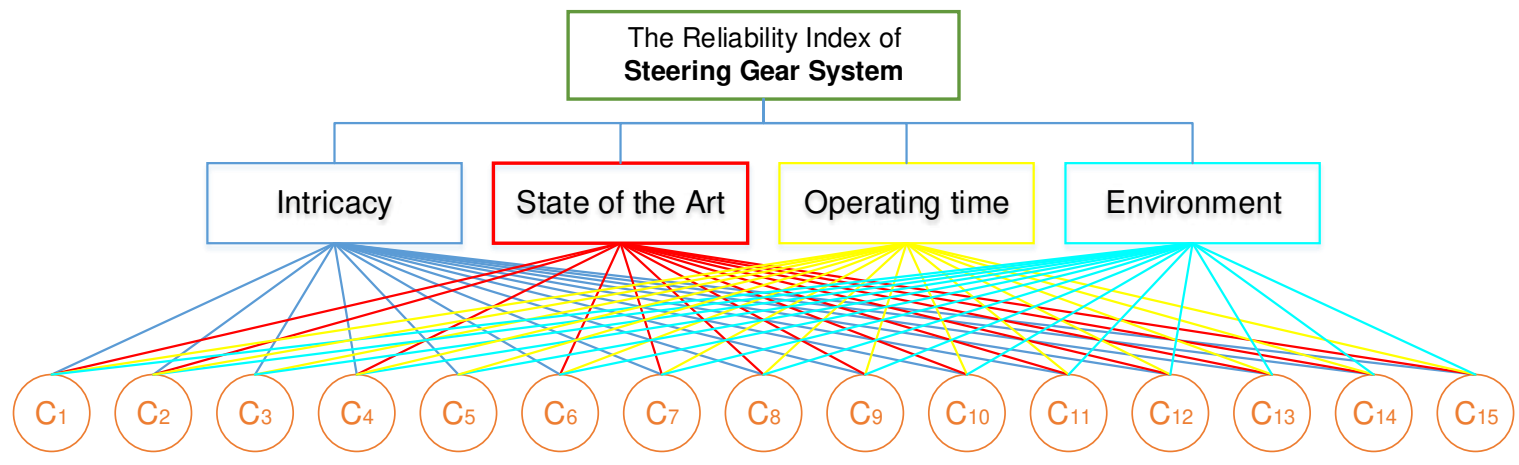

Figure 2. Hierarchical structure 
After construction the hierarchical structure, as a first step, the importance degrees of RAFs were determined by AHP. The pairwise comparison matrix were obtained through expert judgements using the Saaty's scale of relative importance presented in Table 1 as follows:



From the pairwise comparison matrix A, the scale of importance degrees was obtained by solving for the principal eigenvector of the matrix and then normalizing the result. The results were obtained as follows; maximum eigenvalue was $\lambda_{\max }=4.118465665$, the corresponding normalized principal right eigenvector was $\mathrm{W}=(0.56,0.26,0.12,0.06)^{\mathrm{T}}$, the consistency index of the paired comparison matrix was $\mathrm{CI}=0.039488555$ and the corresponding consistency ratio was $\mathrm{CR}=0.044$. With the fact that $\mathrm{CR}<0.1$, the above pairwise comparison matrix was thought to have acceptable consistency and its normalized principal right eigenvector can be used as the importance degrees of RAFs.

Following with the determination of the importance degrees of RAFs, as a second step, the components were assessed one by one against the RAFs. The assessment was done by experts in maritime industry. The experts from ship machinery manufacturers invited to evaluate the component of the steering gear system against the intricacy and state of the art factors and marine engineers took part in the assessment of the components against operating time and environment factors. The proposed approach provides great flexibility in the number of experts invited to make assessment of component for each RAF. In the study, 15 experts from ship machinery manufacturers and 15 marine engineers as an operator of the steering gear system were joined the evaluation. The judgements of experts formed a distribution assessment matrix which is illustrated in Table 6 . 
Table 6. Distribution assessment matrix for components

\begin{tabular}{|c|c|c|c|c|c|c|c|c|c|c|c|c|c|c|c|c|}
\hline \multirow{3}{*}{ Components } & \multicolumn{16}{|c|}{ Reliability Allocation Factors } \\
\hline & \multicolumn{4}{|c|}{$\mathbf{R A F}_{1}$} & \multicolumn{4}{|c|}{$\mathbf{R A F}_{2}$} & \multicolumn{4}{|c|}{$\mathbf{R A F}_{3}$} & \multicolumn{4}{|c|}{$\mathbf{R A F}_{4}$} \\
\hline & VS & $\mathrm{S}$ & $\mathrm{C}$ & $\mathrm{VC}$ & VL & $\mathrm{L}$ & $\mathrm{H}$ & $\mathrm{VH}$ & $\mathrm{VL}$ & $\mathrm{L}$ & $\mathrm{H}$ & $\mathrm{VH}$ & LS & MS & $S$ & VS \\
\hline $\mathbf{C}_{1}$ & & 7 & 6 & 2 & & & 7 & 8 & & 2 & 6 & 7 & 12 & 3 & & \\
\hline $\mathbf{C}_{2}$ & & 6 & 6 & 3 & & 4 & 5 & 6 & & 2 & 6 & 7 & 12 & 3 & & \\
\hline $\mathbf{C}_{3}$ & & 4 & 9 & 2 & & 1 & 7 & 7 & & 1 & 7 & 7 & 12 & 3 & & \\
\hline $\mathrm{C}_{4}$ & & 4 & 11 & 1 & & & 5 & 10 & & & 7 & 8 & 11 & 2 & 2 & \\
\hline $\mathbf{C}_{5}$ & 1 & 5 & 6 & 3 & & 5 & 5 & 5 & & & 1 & 14 & 6 & 5 & 4 & \\
\hline$C_{6}$ & & 7 & 8 & & 2 & 3 & 5 & 5 & & & 1 & 14 & 6 & 5 & 4 & \\
\hline $\mathbf{C}_{7}$ & 5 & 8 & 2 & & & 5 & 8 & 2 & 1 & 4 & 5 & 5 & 2 & 4 & 6 & 3 \\
\hline $\mathrm{C}_{8}$ & 12 & 3 & & & & 3 & 9 & 3 & 1 & 4 & 5 & 5 & 5 & 5 & 5 & \\
\hline C9 & 7 & 8 & & & & 5 & 6 & 4 & & 3 & 6 & 6 & 6 & 5 & 4 & \\
\hline $\mathrm{C}_{10}$ & 5 & 6 & 4 & & & 4 & 6 & 5 & 3 & 3 & 4 & 5 & 8 & 5 & 2 & \\
\hline$C_{11}$ & 5 & 6 & 4 & & & 5 & 5 & 5 & 2 & 3 & 5 & 5 & 8 & 5 & 2 & \\
\hline$C_{12}$ & 6 & 9 & & & & 4 & 6 & 5 & 9 & 6 & & & 8 & 5 & 2 & \\
\hline $\mathbf{C}_{13}$ & 5 & 10 & & & 1 & 4 & 7 & 3 & 3 & 3 & 5 & 4 & 3 & 5 & 5 & 2 \\
\hline $\mathrm{C}_{14}$ & 6 & 9 & & & 1 & 2 & 7 & 5 & 3 & 3 & 5 & 4 & 3 & 5 & 5 & 2 \\
\hline $\mathrm{C}_{15}$ & 4 & 10 & & & 2 & 2 & 8 & 3 & 3 & 3 & 5 & 4 & 3 & 5 & 5 & 2 \\
\hline
\end{tabular}

The distribution assessment matrix was solved with model (6) to generate the individual reliability ratings of components. For intricacy criterion, we had the following optimal solution:

$\mathrm{s}^{*}(\mathrm{VS})=0.069, \mathrm{~s}^{*}(\mathrm{~S})=0.034, \mathrm{~s}^{*}(\mathrm{C})=0.023, \mathrm{~s}^{*}(\mathrm{VC})=0.017$

As such, the following optimal solution had been obtained from model (6) for state of the art, operating time and environmental condition factor, respectively.

$\mathrm{s}^{*}(\mathrm{VL})=0.080, \mathrm{~s}^{*}(\mathrm{~L})=0.040, \mathrm{~s}^{*}(\mathrm{H})=0.027, \mathrm{~s}^{*}(\mathrm{VH})=0.020$

$\mathrm{s}^{*}(\mathrm{VL})=0.069, \mathrm{~s}^{*}(\mathrm{~L})=0.034, \mathrm{~s}^{*}(\mathrm{H})=0.023, \mathrm{~s}^{*}(\mathrm{VH})=0.017$

$\mathrm{s}^{*}(\mathrm{VS})=0.115, \mathrm{~s}^{*}(\mathrm{~S})=0.058, \mathrm{~s}^{*}(\mathrm{C})=0.019, \mathrm{~s}^{*}(\mathrm{VC})=0.005$

Based upon the above optimal solutions, the individual reliability ratings of steering gear components were calculated by equation (5) and obtained results are presented in Table 7. 
Table 7. Individual reliability ratings of steering gear components

\begin{tabular}{ccccc}
\hline Component & $\mathrm{RAF}_{1}(0.56)$ & $\mathrm{RAF}_{2}(0.26)$ & $\mathrm{RAF}_{3}(0.12)$ & $\mathrm{RAF}_{4}(0.02)$ \\
\hline $\mathbf{C}_{\mathbf{1}}$ & 0.736 & 0.920 & 0.736 & 0.370 \\
$\mathbf{C}_{\mathbf{2}}$ & 0.736 & 0.787 & 0.736 & 0.423 \\
$\mathbf{C}_{\mathbf{3}}$ & 0.747 & 0.867 & 0.747 & 0.375 \\
$\mathbf{C}_{\mathbf{4}}$ & 0.793 & 1.000 & 0.793 & 0.500 \\
$\mathbf{C}_{\mathbf{5}}$ & 1.000 & 0.733 & 1.000 & 0.620 \\
$\mathbf{C}_{\mathbf{6}}$ & 1.000 & 0.720 & 1.000 & 0.769 \\
$\mathbf{C}_{\mathbf{7}}$ & 0.626 & 0.613 & 0.626 & 0.923 \\
$\mathbf{C}_{\mathbf{8}}$ & 0.626 & 0.680 & 0.626 & 0.981 \\
$\mathbf{C}_{\mathbf{9}}$ & 0.759 & 0.693 & 0.759 & 1.000 \\
$\mathbf{C}_{\mathbf{1 0}}$ & 0.603 & 0.747 & 0.603 & 0.813 \\
$\mathbf{C}_{\mathbf{1 1}}$ & 0.621 & 0.733 & 0.621 & 0.447 \\
$\mathbf{C}_{\mathbf{1 2}}$ & 0.293 & 0.747 & 0.293 & 0.519 \\
$\mathbf{C}_{\mathbf{1 3}}$ & 0.569 & 0.647 & 0.569 & 0.702 \\
$\mathbf{C}_{\mathbf{1 4}}$ & 0.569 & 0.753 & 0.569 & 0.736 \\
$\mathbf{C}_{\mathbf{1 5}}$ & 0.569 & 0.653 & 0.569 & 0.755 \\
\hline
\end{tabular}

After calculation of the individual reliability ratings $\left(v_{i j}\right)$ of steering gear components, they were aggregated into overall reliability ratings $\left(W\left(C_{i}\right)\right)$ using Eq (7). The overall reliability ratings were presented in column 2 of Table 8 . With the help of obtained overall reliability ratings, the complexity factor $\left(C_{i}\right)$ of each component was calculated by Eq (8) and illustrated in column 3 of Table 8 .

In the MSc. thesis of Brocken in 2016, it was found that, steering gear system failure behavior is suited to the exponential failure distribution and reliability requirement $\left(R_{s}\right)$ was accepted 0.90 for 1000 hours' operation time (Brocken, 2016). Under the lights of this information, system failure rate of steering gear system $\left(\lambda_{s}\right)$ was found as 105.361. Following with the system failure rate, as a final step, allocated failure rate $\left(\lambda_{i}\right)$ and allocated reliability rate $\left(R_{i}\right)$ of each component was calculated using Eq (9). The obtained results were presented in column 4 and 5 respectively in table 8 . 
Table 8. Allocated reliability of steering gear components

\begin{tabular}{ccccc}
\hline Components & $\mathbf{W}\left(\mathbf{C}_{\mathbf{i}}\right)$ & $\mathbf{C}_{\mathbf{i}}^{\prime}$ & $\boldsymbol{\lambda}_{\mathbf{i}}$ & $\mathbf{R}_{\mathbf{i}}$ \\
\hline $\mathbf{C}_{\mathbf{1}}$ & 0.7616 & 0.0725 & 7.6424 & 0.9924 \\
$\mathbf{C}_{\mathbf{2}}$ & 0.7301 & 0.0695 & 7.3264 & 0.9927 \\
$\mathbf{C}_{\mathbf{3}}$ & 0.7559 & 0.0720 & 7.5845 & 0.9924 \\
$\mathbf{C}_{\mathbf{4}}$ & 0.8293 & 0.0790 & 8.3214 & 0.9917 \\
$\mathbf{C}_{5}$ & 0.9079 & 0.0865 & 9.1097 & 0.9909 \\
$\mathbf{C}_{\mathbf{6}}$ & 0.9134 & 0.0870 & 9.1647 & 0.9909 \\
$\mathbf{C}_{\mathbf{7}}$ & 0.6408 & 0.0610 & 6.4301 & 0.9936 \\
$\mathbf{C}_{\mathbf{8}}$ & 0.6616 & 0.0630 & 6.6388 & 0.9934 \\
$\mathbf{C}_{\mathbf{9}}$ & 0.7561 & 0.0720 & 7.5871 & 0.9924 \\
$\mathbf{C}_{\mathbf{1 0}}$ & 0.6532 & 0.0622 & 6.5545 & 0.9935 \\
$\mathbf{C}_{\mathbf{1 1}}$ & 0.6396 & 0.0609 & 6.4174 & 0.9936 \\
$\mathbf{C}_{\mathbf{1 2}}$ & 0.4246 & 0.0404 & 4.2604 & 0.9957 \\
$\mathbf{C}_{13}$ & 0.5971 & 0.0569 & 5.9918 & 0.9940 \\
$\mathbf{C}_{\mathbf{1 4}}$ & 0.6269 & 0.0597 & 6.2903 & 0.9937 \\
$\mathbf{C}_{\mathbf{1 5}}$ & 0.6021 & 0.0573 & 6.0410 & 0.9940 \\
\hline
\end{tabular}

Following the obtained results, $\mathrm{C}_{12}$, safety valve, was found as a highest reliable component of steering gear system. The higher allocated reliability value indicates the vulnerability of the component. On the other hand, $\mathrm{C}_{5}$, pump, and $\mathrm{C}_{6}$, electric motor, were found as the lowest reliable components of steering gear system. To maintain the steering gear system reliability at 0.90 , it is essential to sustain the components' allocated reliability at calculated degrees. Also, to improve the reliability of steering gear system, it is necessary to provide more attention to increase reliability the components with the lower reliability values.

The obtained results through the reliability allocation analysis clearly propound the possible improvement points on steering gear system to enhance the system reliability from the perspective of ship machinery manufacturers. Besides, the results lay bare the potential error prone components on steering gear system which are necessary to show more attention during the operation of the system from the perspective of marine engineers as an operator of the system.

The reliability allocation analysis results clearly propound the possible improvement points on steering gear system to enhance the system reliability from the perspective of shipboard system manufacturers. Besides, the results lay bare the potential error prone components on steering gear system which are necessary to show more attention during the operation of the system from the perspective of marine engineers as an operator of the system. 


\section{Sensitivity Analysis}

Following with the demonstration of the proposed approach, a sensitivity analysis is carried out to test the changes in allocated reliability rates caused by the variation of the importance degrees and to figure out the influence of the importance degrees on the allocation analysis. Therefore, four different scenarios were developed and, in the scenarios, four different importance degree sets were assigned to RAFs. In Scenario 1 the importance degrees of RAFs were accepted as follows: $\mathrm{RAF}_{1}: 056, \mathrm{RAF}_{2}: 0.26, \mathrm{RAF}_{3}: 0,12, \mathrm{RAF}_{4}: 0.06$; In Scenario $2: \mathrm{RAF}_{1}: 03, \mathrm{RAF}_{2}: 0.3, \mathrm{RAF}_{3}: 0,2, \mathrm{RAF}_{4}: 0.2$; In Scenario 3 : $\mathrm{RAF}_{1}: 025, \mathrm{RAF}_{2}: 0.25$, $\mathrm{RAF}_{3}: 0,25, \mathrm{RAF}_{4}: 0.25$ and in Scenario4: $\mathrm{RAF}_{1}: 0.1, \mathrm{RAF}_{2}: 0.2, \mathrm{RAF}_{3}: 0.30, \mathrm{RAF}_{4}: 0.40$ were accepted. The results of the scenarios; failure rates and allocated reliabilities of components; are tabulated in Table 9. Figure 3 represents the variations in the failure rates of the components and Figure 4 shows the components' reliabilities.



Figure 3. Failure rates of components under different RAFs weights

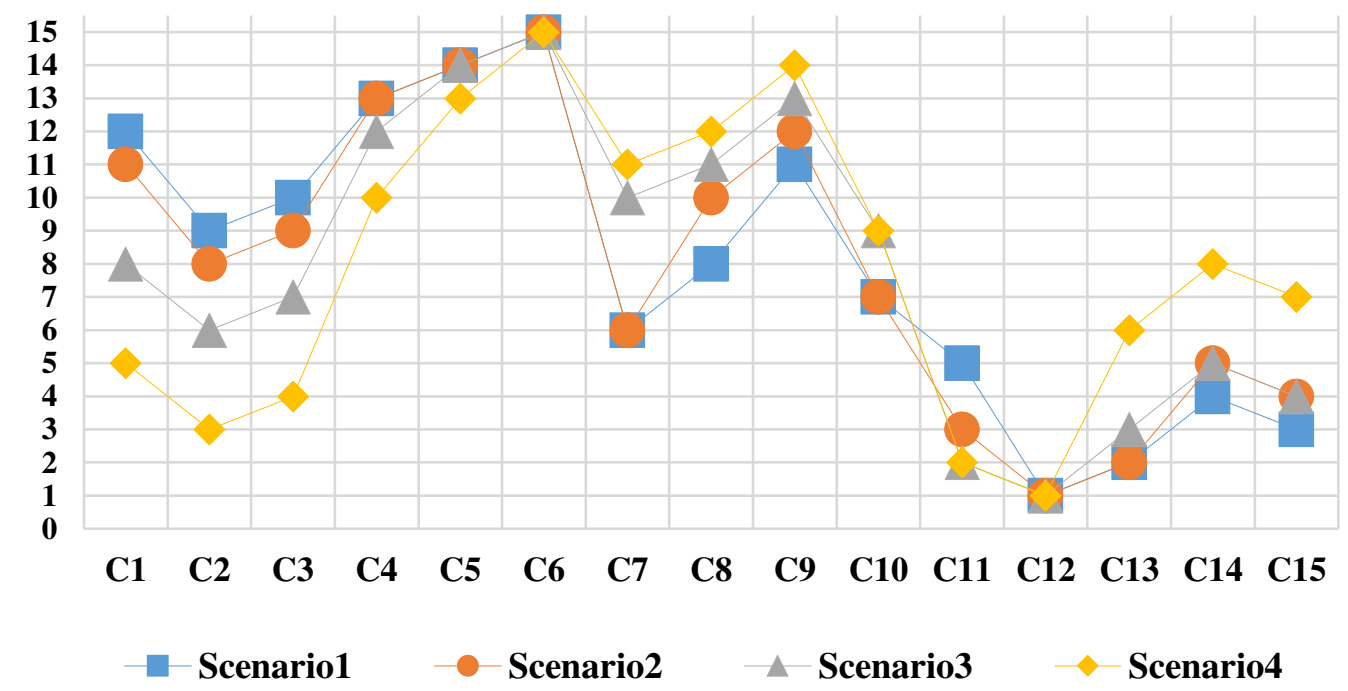

Figure 4. Ranking of components respect to reliabilities under different RAFs weights 
Table 9. Failure rate and reliability of components under different RAFs weightages

\begin{tabular}{|c|c|c|c|c|c|c|c|c|c|c|c|c|}
\hline \multirow[b]{2}{*}{ Component } & \multicolumn{3}{|c|}{ Scenario1 } & \multicolumn{3}{|c|}{ Scenario2 } & \multicolumn{3}{|c|}{ Scenario3 } & \multicolumn{3}{|c|}{ Scenario4 } \\
\hline & $\lambda_{\mathrm{k}}$ & $\mathbf{R}_{\mathbf{i}}$ & Rank & $\lambda_{\mathrm{k}}$ & $\mathbf{R}_{\mathbf{i}}$ & Rank & $\lambda_{\mathrm{k}}$ & $\mathbf{R}_{\mathbf{i}}$ & Rank & $\lambda_{\mathrm{k}}$ & $\mathbf{R}_{\mathbf{i}}$ & Rank \\
\hline C1 & 7.64237 & 0.99239 & 12 & 7.20450 & 0.99282 & 11 & 6.9738 & 0.9931 & 8 & 6.3879 & 0.9936 & 5 \\
\hline $\mathrm{C2}$ & 7.32636 & 0.99270 & 9 & 6.90920 & 0.99311 & 8 & 6.7706 & 0.9933 & 6 & 6.3316 & 0.9937 & 3 \\
\hline $\mathbf{C 3}$ & 7.58455 & 0.99244 & 10 & 7.11125 & 0.99291 & 9 & 6.9093 & 0.9931 & 7 & 6.3456 & 0.9937 & 4 \\
\hline C4 & 8.32136 & 0.99171 & 13 & 7.99431 & 0.99204 & 13 & 7.7939 & 0.9922 & 12 & 7.3151 & 0.9927 & 10 \\
\hline C5 & 9.10972 & 0.99093 & 14 & 8.47090 & 0.99156 & 14 & 8.4690 & 0.9916 & 14 & 8.1055 & 0.9919 & 13 \\
\hline C6 & 9.16466 & 0.99088 & 15 & 8.72991 & 0.99131 & 15 & 8.8117 & 0.9912 & 15 & 8.6863 & 0.9914 & 15 \\
\hline C7 & 6.43012 & 0.99359 & 6 & 6.84299 & 0.99318 & 6 & 7.0441 & 0.9930 & 10 & 7.5724 & 0.9925 & 11 \\
\hline $\mathrm{C8}$ & 6.63878 & 0.99338 & 8 & 7.15951 & 0.99287 & 10 & 7.3581 & 0.9927 & 11 & 7.9437 & 0.9921 & 12 \\
\hline C9 & 7.58705 & 0.99244 & 11 & 7.90156 & 0.99213 & 12 & 8.1080 & 0.9919 & 13 & 8.5886 & 0.9914 & 14 \\
\hline C10 & 6.55454 & 0.99347 & 7 & 6.90712 & 0.99312 & 7 & 6.9854 & 0.9930 & 9 & 7.2995 & 0.9927 & 9 \\
\hline C11 & 6.41742 & 0.99360 & 5 & 6.22008 & 0.99380 & 3 & 6.1161 & 0.9939 & 2 & 5.8520 & 0.9942 & 2 \\
\hline $\mathrm{C} 12$ & 4.26044 & 0.99575 & 1 & 4.76113 & 0.99525 & 1 & 4.6773 & 0.9953 & 1 & 4.8370 & 0.9952 & 1 \\
\hline C13 & 5.99180 & 0.99403 & 2 & 6.21105 & 0.99381 & 2 & 6.2795 & 0.9937 & 3 & 6.5037 & 0.9935 & 6 \\
\hline C14 & 6.29034 & 0.99373 & 4 & 6.59975 & 0.99342 & 5 & 6.6338 & 0.9934 & 5 & 6.8586 & 0.9932 & 8 \\
\hline C15 & 6.04103 & 0.99398 & 3 & 6.33727 & 0.99368 & 4 & 6.4299 & 0.9936 & 4 & 6.7331 & 0.9933 & 7 \\
\hline
\end{tabular}


The results demonstrated that the variation in the RAFs' importance degrees influences allocated reliability ratings. For example, while transmitter $\left(C_{13}\right)$ is the $2^{\text {nd }}$ highest reliable component in Scenario, 1 , it became $6^{\text {th }}$ highest reliable component in Scenario4. Additionally, tiller $\left(C_{15}\right)$ became $3^{\text {rd }}$ reliable component in Scenario 1 , $4^{\text {th }}$ reliable component in Scenario 2 and $\mathrm{Scnerario}_{3}$ and $7^{\text {th }}$ reliable component in Scenario4. On the other hand, safety valve $\left(C_{12}\right)$ became highest reliable and electric motor $\left(C_{6}\right)$ became lowest reliable components in all scenarios.

According to the sensitivity analysis, this research finds that the determination of the importance degrees of RAFs respect to the characteristics of analysed system is one of the essential points in reliability allocation analysis. Additionally, it is understood that, the proposed approach is sufficient robust and could be easily implemented in practices for reliability allocation analysis problems. Reliability practitioners can more effectively form their decision structure and detect the core component/components on the system which is/are needed to focus on.

\section{Conclusion}

Reliability of ship-board systems has always been a significant concern for safety practitioners and researchers since potential failures of ship-board systems often leads to catastrophic consequences. Therefore, reliability researchers have strong tendency to seek proactive solution to prevent unexpected consequences in conjunction with system failures. At this insight, we propose a new reliability allocation approach for ship-board systems by taking advantage of knowledge-based system in order to transform theoretical information into practical solution. The proposed approach combines AHP and DEA by adopting FOO approach. Whilst the AHP method provides a hierarchal conceptual framework to analyze the system, the DEA method quantifies local reliability rates of each system component. Moreover, the proposed approach offers an advantage on linguistic assessment scale to minimize the uncertainty and ambiguity in allocation analysis. The demonstration of the proposed approach is illustrated on steering gear system as a one of the critical shipboard systems.

The important aspect of the approach is the ability to assess different factors by different numbers of experts and different numbers of assessment grades. It integrates the importance degrees of allocation factors into the assessment, since different system may require different importance among defined allocation factors. The generic and simple 
structure of the approach has led to implement not only for shipboard systems but also for other made-to-order engineering systems.

The approach enables to user a proactive user-friendly solution on enhancement the reliability of ship-board systems. Thus, the approach is expected to encourage shipboard organization by monitoring and identifying shipboard system failure rates on-board ship. Respectively, remedial measures will be taken in advance to mitigate the system failure and enhance system reliability simultaneously in ship operational level.

Consequently, the paper presents a theoretical contribution on reliability allocation for shipboard systems via knowledge-based system. The approach is applicable to critical shipboard systems such as electricity, power generation, steam generation and compressed air systems where system failure rates are relatively high. Also, the outcomes of the paper contribute the research studies on reliability centered maintenance system on shipboard systems.

\section{Declarations}

\section{Availability of data and materials}

Not applicable.

\section{Competing interests}

I have no competing interests.

\section{Funding}

No funding was received for this work.

\section{Authors' contribution}

Not applicable.

\section{Acknowledgement}

The authors acknowledge the contribution of the industrial experts without whom this study could not be accomplished. 


\section{REFERENCES}

Advisory Group of Reliability of Electronic Equipment, (AGREE) (1957). Reliability of military electronic equipment. Office of the Assistant Secretary of Defense Research and Engineering, Washington, DC.

Aldamak, A.M., \& Zolfaghari, S. (2017). Review of efficiency ranking methods in data envelopment analysis. Measurement, 106, 161-172.

Alven, W.H. (1964). Reliability engineering: Prepared by ARINC research corporation. Englewood Cliff, NJ: Prentice Hall, Inc.

Anderson, R. T. (1976). Reliability design handbook. Chicago: ITT Research Institute.

Balaban, H.S., \& Jeffers H.R. (1999). The allocation of System Reliability. Vol. I. Development of Procedures for Reliability Allocation and Testing. ARINC Research Corp Washington DC.

Bari, R.A., Cho, N.Z., \& Papazoglou, I.A. (1985). Reliability allocation in nuclear power plants. Transactions of the International Conference on Structural Mechanics in Reactor Technology, M1-M2, 545-550.

Boyd J.A. (1992). Allocation of Reliability Requirements: a new approach. Annual Reliability and Maintainability Symposium 1992 Proceedings, Las Vegas, NV, 5-6.

Bracha, V. J. (1964). The methods of reliability engineering. Machine Design, 70-76.

Brocken, E.M. (2016). Improving the reliability of ship machinery: a step towards unmanned shipping. Master of Science Thesis, Delft University of Technology.

Chang, K.H., Liaw, C.S., Chang, T.Y., \& Chang, Y.C. (2013). FMEA-based DEMATEL apportionment approach. Journal of Chung Cheng Institute of Technology, 42(1), 41-58.

Charnes, A., Cooper, W.W., \& Rhodes, E. (1978). Measuring the efficiency of decision making units. European Journal of Operational Research, 2, 429-444.

Chatterjee, S., Singh, J.B., \& Roy, A. (2015). A structure-based software reliability allocation using fuzzy analytic hierarchy process International Journal of Systems Science, 46(3), 513-525.

Chen, T., Zheng, S., Liao, H., \& Feng, J. (2016). A multi attribute reliability allocation method considering uncertain preferences. Quality and Reliability Engineering International, 32(7), 2233-2244.

Cheng, J., Zhou, F., \& Yang, S. (2014). A reliability allocation model and application in designing a mine ventilation system. Iranian Journal of Science and Technology Transactions of Civil Engineering, 38(C1), 61-73.

Cho, N.Z., Papazoglou, I.A., \& Bari, R.A. (1987). Multiobjective programming approach to reliability allocation for nuclear power plants. Nuclear Science and Engineering, 95(3), 165-188. 
Di Bona, G., \& Forcina, A. (2017). Analytic Critical Flow Method (ACFM): A Reliability Allocation Method Based on Analytic Hierarchy Process. Journal of Failure Analysis and Prevention, 17(6), 1149-1163.

Di Bona, G., Forcina, A., Petrillo, A., De Felice, F., \& Silvestri, A. (2016). A-IFM reliability allocation model based on multicriteria approach. International Journal of Quality \& Reliability Management, 33(5), 676-698.

Di Bona, G., Silvestri, A., Forcina, A., \& Falcone, D. (2017). AHP-IFM Target: An Innovative Method to Define Reliability Target in an Aerospace Prototype Based on Analytic Hierarchy Process. Quality and Reliability Engineering International, 33(8), 1731-1751.

Falcone, D., Silvestri, A., \& Di Bona, G. (2003). Integrated factors method for reliability allocation: A new application to an Aerospace prototype project USA Cambridge.

Falcone, D., Silvestri, A., Di Bona, G., \& Forcina, A. (2018). Mathematical Models for Reliability Allocation and Optimization for Complex Systems. In Human Factors and Reliability Engineering for Safety and Security in Critical Infrastructures, 43-76. Springer, Cham.

Fan, C., Zhou, X.J., \& Wang, X.C. (2014). Reliability allocation of seafloor observation network by using Monte Carlo method. Advanced Materials Research, 926-930, 19972000 .

Feng, Y., Hong, Z., Cheng, J., Tian, G., Zhang, H., \& Tan, J. (2017). Environmentalfriendly reliability allocation for product platform based on expert measurement and ICN. Computers \& Electrical Engineering, 64, 132-144.

Ghodrati, B. (2005). Reliability and operating environment based spare part planning. Doctoral Thesis, Lulea University of Technology Division of Operation and Maintenance Engineering.

Guo, H., Jiang M., \& Wang, W. (2014). A Method for Reliability Allocation with Confidence Level. 2014 Reliability and Maintainability Symposium. Colorado Springs, $\mathrm{CO}, 1-1$.

Karmiol, E. D. (1965). Reliability apportionment. Preliminary Report EIAM-5, Task II, General Electric, Schenectady, NY, 10-22.

Ke-Rong, B., Jiong, Y., \& Ji, W. (2001). Computer system reliability allocation method and supporting tool. Wuhan University Journal of Natural Sciences, 6 (1-2), 505-510.

Kim, K.O. \& Zuo, M.J. (2015). Effects of subsystem mission time on reliability allocation. IIE Transactions, 47(3), 285-293.

Kumral, M. (2005). Reliability-based optimisation of a mine production system using genetic algorithms. Journal of Loss Prevention in the Process Industries, 18 (3), 186-189.

Kuo, H. E. (1999). Reliability assurance: Application for engineering and management (2nd ed.). Chinese Society for Quality, 3/16-3/23. 
Li, P., Li, C., Bai, C., \& Li, T. (2016). Reliability growth allocation method based on fuzzy logic and AHP. Proceedings of 2015 Prognostics and System Health Management Conference, PHM 2015, art. no. 7380054.

Li, R. Y., Li, \& M. N. (2014). Network reliability allocation based on Monte Carlo and heuristic algorithm. Transaction of Beijing Institute of Technology, 34 (7), 695-700.

Li, R., Wang, J., Liao, H., \& Huang, N. A (2015). A new method for reliability allocation of avionics connected via an airborne network. Journal of Network and Computer Applications, 48, 14-21.

Li, T., Zheng, S., Chen, T., Feng, J., \& Zhao, L. (2017). Reliability allocation of fuel cell vehicle based on grey system theory. Journal of Mechanical Strength, 39 (5), 1072-1078.

Li, W., Zeng, Q., Shen, L., \& Zhang, Z.B. (2014). A multi-objective optimization method for system reliability allocation. Advanced Materials Research, 860-863, 2766-2773.

Liang, X.F., Chen, L.Y., Yi, H., \& Li, D. (2015). Integrated allocation of warship reliability and maintainability based on top-level parameters. Ocean Engineering, 110, 195-204.

Liao, H. (2009). Reliability allocation for improving the robustness of an engineering system. International Journal of Performability Engineering, 5 (5), 493-495.

Liaw, C.S., Chang, Y.C., Chang, K.H., \& Chang, T.Y. (2011). ME-OWA based DEMATEL reliability apportionment method. Expert Systems with Applications, 38 (8), 9713-9723.

Liu, C.M., \& Li, J.L. (2003). Fuzzy goal programming for reliability allocation with seriesparallel systems. International Journal of Operations and Quantitative Management, 9 (3), 177-193.

Liu, X.H., Xu, G.H., Ma, C.C., \& Li, S.F. (2007). Reliability allocation and optimization of engine system by using genetic algorithm and Monte Carlo method (2007) Journal of Beijing Institute of Technology (English Edition), 16 (3), 268-273.

Lu, X., Li, X., \& Lin, F. (2004). Reliability allocation and optimization for complex systems. Journal of Beijing University of Aeronautics and Astronautics, 30(6), 565-568.

Ma, Z., Ren, Y., Liu, L., \& Wang, Z. (2016). A reliability allocation method based on Bayesian networks and Analytic Hierarchy Process. IEEE International Conference on Industrial Engineering and Engineering Management, 83-87.

Malec, H.A., (1977). Reliability Optimization in Telephone Switching Systems Design. IEEE Transactions on Reliability, $R$-26(3), 203-208.

Marah, F.E. (1963). Inherent reliability design practices, reliability apportionment, in Reliability Control in Aerospace Equipment Development. Society of Automotive Engineers, NY, 38, Macmillan, New York.

Qian, W., Yin, X., \& Xie, L. (2012). System reliability allocation based on Bayesian network. Applied Mathematics and Information Sciences, 6 (2 SUPPL.), 611S-617S. 
Rao, S.S., \& Dhingra, A.K. (1992). Reliability and redundancy apportionment using crisp and fuzzy multiobjective optimization approaches. Reliability Engineering and System Safety, 37(3), 253-261.

Saaty, T. L. (1986). Axiomatic foundation of the analytic hierarchy process. Management science, 32(7), 841-855.

Saaty, T.L. (1980). The Analytic Hierarchy Process: Planning, Priority Setting, Resource Allocation. New York: McGraw-Hill.

Saaty, T.L. (1994). How to Make a Decision: The Analytic Hierarchy Process. Interfaces 24(6), 19-43.

Sadeghi, M., Karbasiyan, M., \& Navabakhsh, M. (2014). Designing a model for reliability improvement with FTA and FMEA techniques on medical gas outlet. International Journal of Logistics Systems and Management, 18 (3), 322-342.

Sae Subcommittee on Reliability Society of Automotive Engineers (SSRCAE), (1964). Reliability control in aerospace equipment development: a guide for development engineers. 2nd ed. Society of Automotive Engineers.

Sakawa, M. (1978). Multiobjective Optimization by the Surrogate Worth Trade-off Method. IEEE Transactions on Reliability, R-27(5), 311-314.

Sangeetha, M., Arumugam, C., Kumar, K.M.S., \& Shankar, S.H. (2014). An effective approach to support multi-objective optimization in software reliability allocation for improving quality. Procedia Computer Science, 47 (C), 118-127.

Silvestri, A., Falcone, D., Di Bona, G., Forcina, A., Cerbaso, C., \& Duraccio, V. (2015). A new method for reliability allocation: Critical flow method. Lecture Notes in Mechanical Engineering, 20, 249-261.

Subhashis C., Jeetendra B. S. \& Arunava, R. (2015). A structure based software reliability allocation using fuzzy analytic hierarchy process. International Journal of Systems Science, 46:3, 513-525.

Wang, H., Zhang, Y., Yang, Z., \& Zhou, Y. (2016). Reliability allocation of key subsystems of CNC lathes based on FMECA modified criticality. Zhongguo Jixie Gongcheng/China Mechanical Engineering, 27(14), 1936-1941.

Wang, Y. M., Chin, K. S., \& Yang, J. B. (2007). Three new models for preference voting and aggregation. Journal of the Operational Research Society, 58(10), 1389-1393.

Wang, Y.M., Liu, J. and Elhag, \& Taha, M.S. (2008) An integrated AHP-DEA methodology for bridge risk assessment. Computers \& Industrial Engineering, 54(3), 513 525 .

Xu, G.H., Liu, X.H., \& Li, X.J. (2007). Reliability allocation of crank mechanism based on GA. Chinese Internal Combustion Engine Engineering, 28(2), 60-64.

Yadav, O.P., \& Zhuang, X. (2014). A practical reliability allocation method considering modified criticality factors. Reliability Engineering \& System Safety, 129, 57-65. 
Yang, J.B. (2001). Rule and utility based evidential reasoning approach for multiattribute decision analysis under uncertainties. European Journal of Operational Research, 131(1): $31-61$.

Yang, J.E., Hwang, M.J., Sung, T.Y., \& Jin, Y. (1999). Application of genetic algorithm for reliability allocation in nuclear power plants. Reliability Engineering and System Safety, 65 (3), 229-238.

Zahedi, F., \& Ashrafi, N. (1991). Software Reliability Allocation Based on Structure, Utility, Price, and Cost. IEEE Transactions on Software Engineering, 17 (4), 345-356.

Zavala, A.E.M., Diharce, E.R.V., \& Aguirre, A.H. (2005). Particle evolutionary swarm for design reliability optimization. Lecture Notes in Computer Science, 3410, 856-869.

Zhang, G.B., \& Liao, X.B. (2009). Research on reliability allocation of direct-drive hobbing machine. Materials Science Forum, 628-629, 245-250.

Zhang, Y., Jia, J., \& Huang, X. (2016). Reliability allocation of cnc lathe based on edgeworth series method and date envelopment analysis. Journal of Mechanical Strength, 38 (1), 69-73.

Zhao, J.H., Dao, T.M., \& Liu, Z. (2005). Optimization of mechanical systems reliability using ant colony based simulation approach. Proceedings of the IASTED International Conference on Modelling and Simulation, art. no. 459-118, 182-187.

Zia, L., \& Coit, D.W. (2006). A general column generation algorithm applied to system reliability optimization problems. 2006 IIE Annual Conference and Exhibition, 6 p.

Zio, E., \& Bazzo, R. (2011). A clustering procedure for reducing the number of representative solutions in the Pareto Front of multiobjective optimization problems. European Journal of Operational Research, 210 (3), 624-634. 




Figure 1

Framework of the methodology 


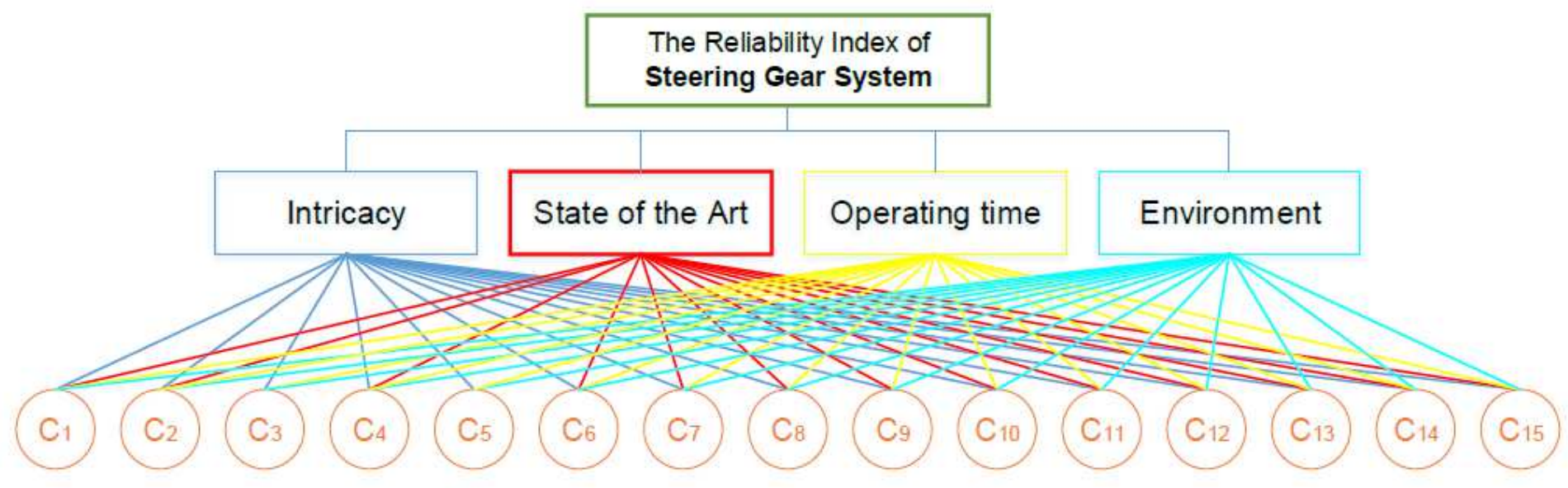

Figure 2

Hierarchical structure

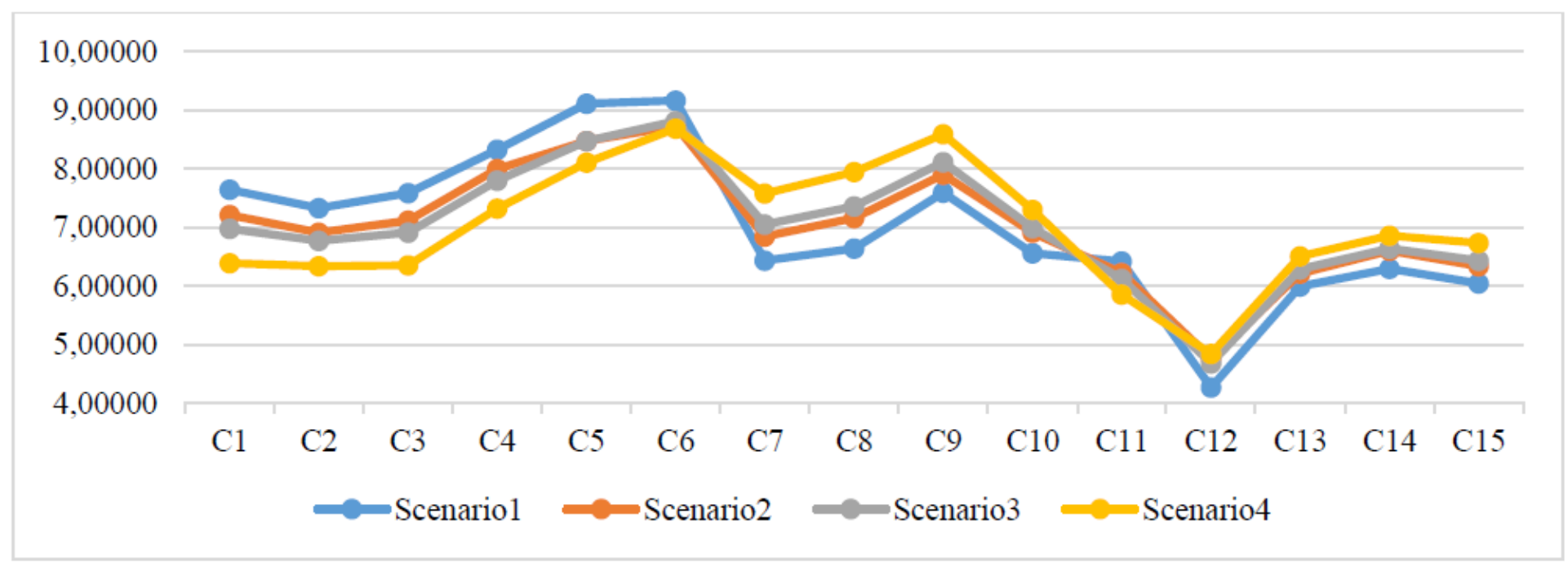

\section{Figure 3}

Failure rates of components under different RAFs weights 


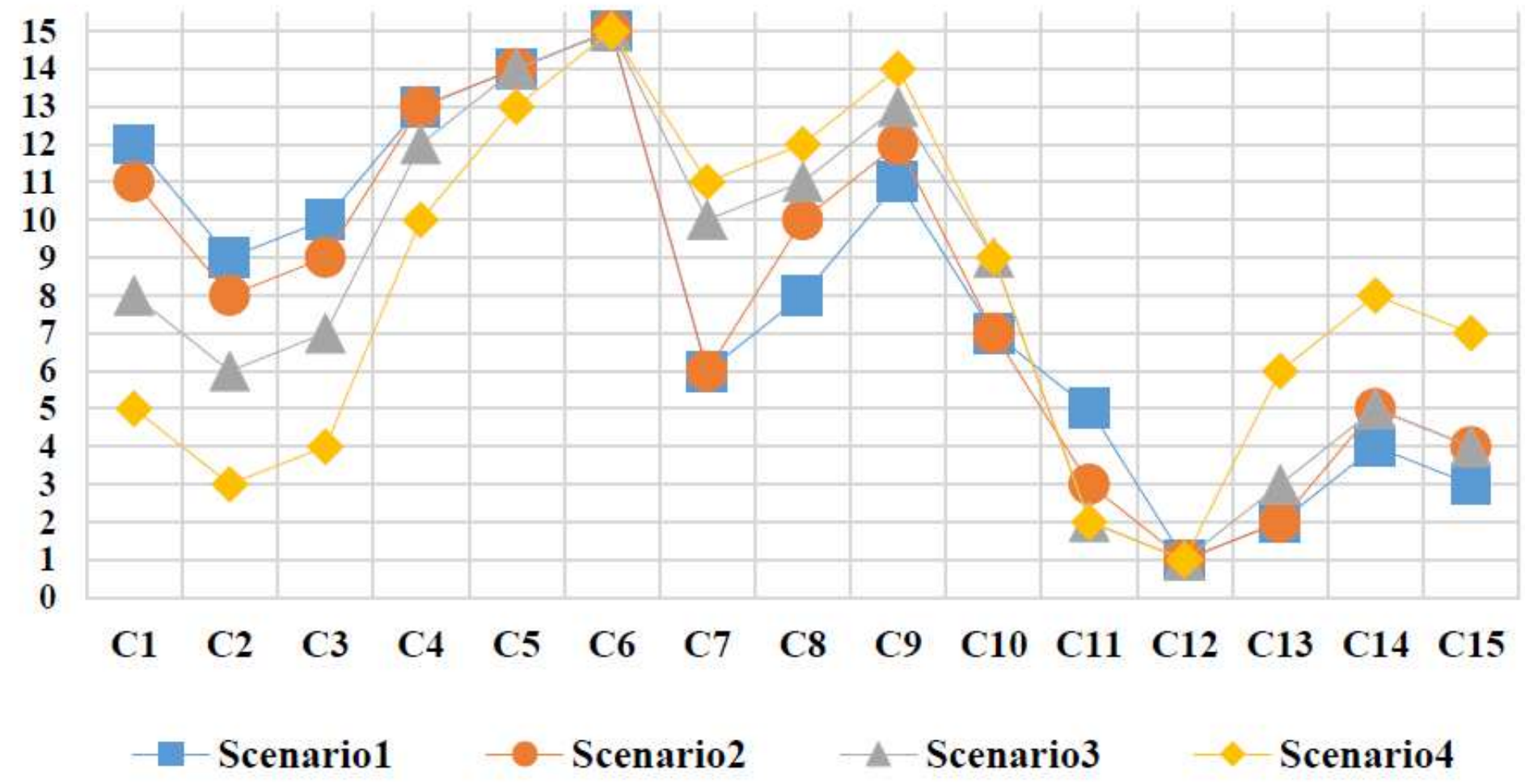

Figure 4

Ranking of components respect to reliabilities under different RAFs weights 